\title{
Assessment of Depression and Stress Symptoms among Mothers of Premature Infants Admitted to Neonatal Intensive Care Unit
}

\author{
Salwa Samy ShiabEl-Din ${ }^{1}$,Ghada Mohamed Mourad², Wafaa Osman \\ Abd El-Fatah ${ }^{3}$ \\ ${ }^{1}$ Demonstrator in Psychiatric /Mental Health Nursing, Faculty of Nursing, Helwan University \\ ${ }^{2}$ Professor of Psychiatricl Mental Health Nursing, Faculty of Nursing, Ain-Shams University, \\ ${ }^{3}$ Lecturer of Psychiatric/ Mental Health NursingNursing, Faculty of Nursing, Helwan University.
}

\section{Abstract}

Background: Premature birth is highly stressful experience for mothers and elevated level of stress and depressive symptoms for mothers. the aim of this study was to assess depression, stress symptoms among mothers of premature infants admitted to neonatal intensive care unit. Design: a descriptive exploratory design was utilized in this study. Setting: the study was conducted at neonatal intensive care unit at Sidi Salem general hospital. Subject: the sample consisted of 90 mothers of premature infant selected from neonatal intensive care unit. Tools: three tools were used for data collection: tool (1): socio demographic sheet Tool (2): parental stress scale is used to assess mothers stress and perception related to neonatal intensive care unit. Tool (3): the Edinburgh post natal depression scale is used to identify depressive symptoms among mothers. Results: the result of present study, revealed that two fifth of Mothers at Risk exposure to high level of stress related to admission of infant to Neonatal intensive care unit .there is statistically significance relation between mother age and resident with Level of depression .Conclusion: this study concluded that statistically high significant relation between level of total stress and total depression among mothers under this study, correlation between mother's total score depression and total score of stress show positive correlation and high significant between mother's total score of depression and total score of stress. Recommendations: -design training programs for mother of premature baby at neonatal intensive care unit improves psychological status and -psychosocial education programs by providers and hospital administration about prevalence of postpartum depression and its impact and benefits of screening.

Key words: Depression, stress, premature infants, neonatal intensive care unit ,Mother of Premature infant. 


\section{Tanta Scientific Nursing Journal}

\section{Introduction:}

Premature birth is often a traumatic event for mothers that could cause in traumarelated symptoms, such as symptoms of avoidance, intrusion andhyper-arousa1, negative states of mind and feelings, such as anxiety, hostility, inertia, depression, and bewilderment, and stress related to the Neonata1 Intensive Care Unit (NICU) perception, the baby's conditions and the perception of an altered parental role $\mathrm{e}^{(\mathbf{1}) \text {. }}$

Premature birth, whether planned or unplanned, may result maternal guilt and failure to deliver a healthy baby, this triggers negative maternal emotion responses such as depressive symptoms and stress, mother also experience feeling of being uncertain about infant outcome, lack information and miscommunication with providers ${ }^{(2) .}$

Depression can affect any mother who has a baby in neonatal intensive care unit although it can be a common problem during stressful time, it can be over looked by health care staff, family, friends, and by the mother herself. The effect of depression rang from mild to severe when it becomes worse not only affects the mother but also all members in her family ,depressive symptoms of mothers have negative effect on their relation with the infant and their parenting role. (3).
When the baby is admitted to NICU, the mother usually feels powerless and helpless, fearful from any medical complication that can occur for her baby. In this time, premature birth becomes a stressful event which threats the physical integrity for the mother. This trauma leads to develop post-traumatic stress symptoms as avoidance, hyper -arousal and intrusion, which prevent mother from having a normative transition to parenthood and damaging relation from isolation about her baby ${ }^{(4)}$.

Mother lives in bad psychological and physical state due to separation from her baby, aggravated by artificial environment in which medical staff take care of the infant neuropsychological and behavioral development and wellbeing. All causes put mothers in pain and distress in the future, so mothers should spend many hours in the NICU to experience the infant fragility and mortality ${ }^{(5)}$.

The mother should keep in touch with others and express her feeling with other such as partners, family members and friends; talking with other keeps stress under control and decreases or prevent the depression. Mother also talks with health staff in neonatal intensive care unit about the baby condition and also shares other parents their stories or experience with 
premature infant, mothers experienceof nurse attitude and her interpersonal skills play role in the relation with baby and neonatal intensive care unit staff ${ }^{(6)}$.

Early Seeking for psychotherapist or a mental health member is important to find the problem to take action for early treatment, mother can also find help at hospital or community. Medical and nursing staff also help mother to get rid of the problem through informing and sharing mother in baby care in neonatal intensive care unit as baby feeding specially when the mother becomes at high risk of being depressed ,this give mother trust about her parent role and become nearly from her baby .Her feeling during this period prepares her to the next visit, mother should agree to make discussion with nurse, also identify the visit scheduling ${ }^{(7)}$.

Nursing role doesn't depend on care in hospital only but also on using telephone consultation to increase support and interaction with mother of premature baby. Consultation through telephone improves mother information and follows up during staying and after discharge from hospital; nurse identifies the mother needs and prepares the plan of baby care ${ }^{(8)}$.

The nurse should provide emotional support and health education for mothers to reduce Intensive symptoms of depression and stress. This is the key nursing role helping mothers to become adaptive with birth of premature infant by involved in care for the baby, additiona1to educational role which change badbelieves aboutneonatal intensive care unit(NICU)through giving information abouthospita1staying, status of the baby anddealing with the baby to give satisfaction about mothers role,nursing staff given education and support by leadership to facilitate understanding and communication with mother and family ${ }^{(9)}$.

\subsection{Significance of the Study}

In Egypt, according to study conducted by(Eman,2011) ${ }^{(10)}$ reported that $58 \%$ of premature babies died during their hospital stay, premature birth is high1y stressful experience for mothers this elevated Level of stress and depressive symptom for mothers, the researcher observed in Side Salem governmental general hospital at neonata1 intensive care unit premature infant sad mission rate (40\%) from all neonatal admission rate. this study gives attention and motivation for further investigation to assess Depression and Stress Symptoms among Mothers of Premature Infants Admitted to Neonatal Intensive Care Unit.

\section{Aim of the study}

- This study was aimed to assess depression and stress symptoms of mothers of premature infants admitted 
to neonata1 intensive care unit at saidi salem general hospital

\section{Research Question:}

The fo1lowing research questions were conducted from this study

1- What are the depression symptoms facing mother of preterm infants admitted to neonata1 intensive care unit?

2- What are the stress symptoms facing mother of preterm infants admitted to neonata1 intensive care unit ?

\section{Subjects and methods:}

\section{Research design:}

A descriptive exploratory design has been utilized to conduct the current study.

\section{Research setting:}

This study was conducted at sidisalem governmental general hospital at neonatal intensive care unit at kafreshiekh city. the Hospital consist of three floors and A garden, the first floor includes: the outpatient clinics and the emergency Department while the second Floor consist of the operation Department, the surgery Department and the neonatal intensive care unit next, the third Floor consist of the medical Department, pediatric Department and the Department of Obstetrics. the administrative units and the Dialysis building, they are adjacent to the main building.

\section{Subjects:}

A convenient sample was selected from neonatal intensive care unit at Sidi Salem general hospital according to were presented at the day of data collecting for the study sample. the sample consist of 90 mother in different age

\section{Methods of data collection}

A structured sheet involved the following:

1. Socio -demographic sheet:-this sheet was designed by the researcher after reviewing literature in the field of psychiatric nursing for the purpose of collects of personal socio demographic and clinical data of maternal and infant characteristics as age, number of pregnancies, number of birth, job, marital status, social status, education level the uterine age, Apgar score.

\section{2-Parental Stress Scale(Berry ,1995) ${ }^{\text {(11). }}$}

This scale developed byBerry (1995) ${ }^{(11)}$ it was adapted by the researcher to assess mothers stress and perception related to neonatal intensive care unit (NICU).

This scale contains from 18 items, represent positive e.g (emotional benefits, personal development)and negative e.g (demand), restriction each item 5 point likert scale ranging from 1 to 5 , point scale strongly disagree, undecided, agree, strongly agree. this scale easy to perform and completed in less than 10 minutes 
administered as interview then calculate all items the score range from 18-90, the higher score gives higher level of stress an lower gives lower level of stress.

-Scoring system:

Mild stress: $<\mathbf{5 0 \%}$.

Moderate stress 50\%-70\%. sever stress $>70 \%$

3- The Edinburgh Postnatal Depression Scale (EPDS) (Wisner,2002) ${ }^{(12):}$

The Edinburgh postnatal depression scale (EPDS) developed by Wisner(2002): was used to identify depressive symptoms among mothers.

The Edinburgh postnatal depression scale is a 10-items, used to detect women at risk for developing postnatal depression, the scale is easy performedless than 10 minutes through administered as interview then calculate all items are scored from 0 to 3 , maximum 30 a score above 13has been validated to have a strong predictive value for detecting women at risk for developing postpartum depression.

-Scoring system:

- Low risk: $<50 \%$.

- Moderate risk:50-70\%.

- High risk:>70\%.

\section{Pilot study}

A pilot study was conducted on $10 \%$ of the study sample to assess the feasibility of the study as well as clarity and objectivity of the tools and applicability of the tools the time needed to complete them and perform the required modifications according to the available resources. Subjects who shared in the pilot study were excluded from the main study sample.

\section{Field of work}

Data collection of this study was carried out at the beginning of December 2017 to the end of june 2018 after acceptance of permission from the ethical and scientific research committee at the general secretariat of Sidi Salem general hospital. The researcher met mothers who agreed to be involved in the study sample. Subjects involved in the study were interviewed and assessed two times per week.

After the permission is taken from the nurse and security members who found in the unit, the researcher introduced himself to the mothers who agreed to be included in this study in order to gain their trust, cooperation and confidence. Voluntary participation and confidentiality were assured by the researcher for each mother through clarifying that all information will be used for scientific research only.

\section{Ethical considerations:}

- Ethical approval obtained from the Scientific, Ethical Committee of Nursing Faculty.

- Ethical approval obtained from the Ethical and Scientific Research 
Committee at the General Secretariat of

Sidi Salem general hospital

- The researcher assured for every selected mother involved in the study sample, that participation is voluntary and that they have the right to withdraw from the study at any time without giving any reason.

- The researcher assured confidentiality of data for every mother involved in the study sample.

- The researcher clarified that all information would be used for scientific research and for the mother benefits.

\section{Data management:}

Recorded data were analyzed using the statistical package for social sciences, version 20.0 (SPSS Inc., Chicago, Illinois, USA). Quantitative data were expressed as mean \pm standard deviation (SD). Qualitative data were expressed as frequency and percentage.

\section{The following tests were done:}

Chi-square (x2) test of significance was used in order to compare proportions between two qualitative parameters.

Spearman's rank correlation coefficient (rs) was used to assess the degree of association between two sets of variables if one or both of them was skewed.
The confidence interval was set to 95\% and the margin of error accepted was set to $5 \%$. So, the p-value was considered significant as the following:

Probability (P-value)

- P-value <0.05 was considered significant.

- P-value $<0.001$ was considered as highly significant.

- P-value >0.05 was considered insignificant..

\section{Results:}

From the current study, the result concluded in:

Table 1 :This table indicated that more than two third ( $64.4 \%$ ) of mothers live in rural area , four fifth of mothers ( $91.1 \%$ ) were married, while education level was more than third (35.6\%) Secondary school more over, more than half of mothers $(58.9 \%)$ were workers, while more than two third ( $66.7 \%$ ) have history of Depression and more than third ( $36.7 \%$ ) of them infant uterine age 29 - 30 weeks , while more than two third ( $66.7 \%$ ) of them not have psychological symptoms .

Table 2: This table shows the percentage distribution of mother's depression among mother's included in this study. As regards to the low risk (50\%), moderate risk (28.9\%) and high risk $(21.1 \%)$ of total depression. 
Table 3 :This table shows the percentage distribution of mother's total positive stress among mother's included in this study. As regards to the mild stress $(27.8 \%)$, moderate stress $(24.4 \%)$ and severe stress $(47.8 \%)$.

Table 4:This table shows the percentage distribution of mother's total negative stress among mother's included in this study. As regards to the mild stress $(21.1 \%)$, moderate stress $(53.3 \%)$ and severe stress $(25.6 \%)$.

Table 5 :This table shows the percentage distribution of mother's total stress among mother's included in this study. As regards to the mild stress $(26.7 \%)$, moderate stress $(34.4 \%)$ and severe stress $(38.9 \%)$. 
Table (1):Distribution of mother's according to their socio-demographic data $(\mathrm{N}=90)$.

\begin{tabular}{|c|c|c|}
\hline Socio-Demographic Data & No. & $\%$ \\
\hline $\begin{array}{l}\text { Age } \text { (years) } \\
\leq 25 \text { years } \\
>25-30 \text { years } \\
>30-35\end{array}$ & $\begin{array}{l}33 \\
35 \\
22\end{array}$ & $\begin{array}{l}36.7 \\
38.9 \\
24.4\end{array}$ \\
\hline $\begin{array}{l}\text { Residence } \\
\text { Rural } \\
\text { Urban }\end{array}$ & $\begin{array}{l}58 \\
32\end{array}$ & $\begin{array}{l}64.4 \\
35.6\end{array}$ \\
\hline $\begin{array}{l}\text { Social status } \\
\text { Married } \\
\text { Widow } \\
\text { Divorced }\end{array}$ & $\begin{array}{c}82 \\
7 \\
1\end{array}$ & $\begin{array}{l}91.1 \\
7.8 \\
1.1\end{array}$ \\
\hline $\begin{array}{l}\text { Education level } \\
\text { Do not read or write } \\
\text { Read and write } \\
\text { Primary } \\
\text { Preparatory } \\
\text { Secondary } \\
\text { University }\end{array}$ & $\begin{array}{c}8 \\
12 \\
4 \\
7 \\
32 \\
27\end{array}$ & $\begin{array}{c}8.9 \\
13.3 \\
4.4 \\
7.8 \\
35.6 \\
30.0\end{array}$ \\
\hline $\begin{array}{l}\text { Job } \\
\text { Worker } \\
\text { Not worker }\end{array}$ & $\begin{array}{l}53 \\
37\end{array}$ & $\begin{array}{l}58.9 \\
41.1\end{array}$ \\
\hline $\begin{array}{l}\text { Number of pregnancies } \\
\text { P1 } \\
\text { P2-3 } \\
\text { P4-P6 }\end{array}$ & $\begin{array}{l}15 \\
57 \\
18\end{array}$ & $\begin{array}{l}16.7 \\
63.3 \\
20.0\end{array}$ \\
\hline $\begin{array}{l}\text { Number of births } \\
\text { Birth 1 } \\
\text { Birth 2-3 } \\
\text { Birth 4-5 }\end{array}$ & $\begin{array}{l}18 \\
62 \\
10\end{array}$ & $\begin{array}{l}20.0 \\
68.9 \\
11.1\end{array}$ \\
\hline $\begin{array}{l}\text { Number of healthy children } \\
\text { Healthy } 1 \\
\text { Healthy } 2-3 \\
\text { Healthy } 4-5\end{array}$ & $\begin{array}{l}30 \\
52 \\
8\end{array}$ & $\begin{array}{c}33.3 \\
57.8 \\
8.9\end{array}$ \\
\hline $\begin{array}{l}\text { History of patients for depression } \\
\text { No } \\
\text { Yes }\end{array}$ & $\begin{array}{l}60 \\
30\end{array}$ & $\begin{array}{l}66.7 \\
33.3\end{array}$ \\
\hline $\begin{array}{l}\text { The uterine age of the intruder } \\
26-28 \mathrm{wks} \\
29-30 \mathrm{wks} \\
>30 \mathrm{wks}\end{array}$ & $\begin{array}{l}31 \\
33 \\
26\end{array}$ & $\begin{array}{l}34.4 \\
36.7 \\
28.9\end{array}$ \\
\hline $\begin{array}{l}\text { The date before the birth of a } \\
\text { premature child } \\
\text { No } \\
\text { Yes }\end{array}$ & $\begin{array}{l}39 \\
51\end{array}$ & $\begin{array}{l}43.3 \\
56.7\end{array}$ \\
\hline $\begin{array}{l}\text { How many times }(\mathbf{N}=\mathbf{5 1}) \\
\text { One } \\
\text { Two }\end{array}$ & $\begin{array}{l}39 \\
12\end{array}$ & $\begin{array}{l}76.5 \\
23.5\end{array}$ \\
\hline
\end{tabular}


Table (2):Distribution of mother's according to their level of total depression ( $N=90)$.

\begin{tabular}{|l|l|l|}
\hline Level of total depression & No. & \% \\
\hline Low risk $<50 \%$ & 45 & 50.0 \\
\hline Moderate risk 50-70\% & 26 & 28.9 \\
\hline High risk $>70 \%$ & 19 & 21.1 \\
\hline Total & 90 & 100.0 \\
\hline Mean \pm SD & $22.36 \pm 5.37$ & \\
\hline
\end{tabular}

Table (3):Distribution of mother's according to their level of total negative stress $(\mathrm{N}=90)$.

\begin{tabular}{|l|c|c|}
\hline Level of total negative stress & No. & \% \\
\hline Mild stress $<50 \%$ & 19 & 21.1 \\
\hline Moderate stress $50-70 \%$ & 48 & 53.3 \\
\hline Severe stress $>70 \%$ & 23 & 25.6 \\
\hline Total & 90 & 100.0 \\
\hline Mean \pm SD & \multicolumn{2}{|c|}{$34.38 \pm 6.88$} \\
\hline
\end{tabular}

Table (4): Distribution of mother's according to their level of total stress (N=90).

\begin{tabular}{|l|c|c|}
\hline Level of total Stress & No. & \% \\
\hline Mild stress <50\% & 24 & 26.7 \\
\hline Moderate stress 50-70\% & 31 & 34.4 \\
\hline Severe stress >70\% & 35 & 38.9 \\
\hline Total & 90 & 100.0 \\
\hline Total & \multicolumn{2}{|c|}{$60.25 \pm 13.04$} \\
\hline
\end{tabular}


Table (5):Relation between mother's levels regarding total depression and their sociodemographic $(\mathrm{N}=90)$.

\begin{tabular}{|c|c|c|c|c|c|c|c|c|c|c|}
\hline \multirow{3}{*}{$\begin{array}{c}\text { Total } \\
\text { depression }\end{array}$} & \multicolumn{6}{|c|}{ Level of total stress } & \multirow{2}{*}{\multicolumn{2}{|c|}{ Total }} & \multirow{2}{*}{\multicolumn{2}{|c|}{ Chi-square test }} \\
\hline & \multicolumn{2}{|c|}{$\begin{array}{l}\text { Mild stress } \\
\quad<50 \%\end{array}$} & \multicolumn{2}{|c|}{$\begin{array}{c}\text { Moderate } \\
\text { stress 50-70\% }\end{array}$} & \multicolumn{2}{|c|}{$\begin{array}{c}\text { Severe stress } \\
>70 \%\end{array}$} & & & & \\
\hline & No. & $\%$ & No. & $\%$ & No. & $\%$ & No. & $\%$ & $\mathbf{x} 2$ & p-value \\
\hline $\begin{array}{ll}\text { Low } & \text { risk } \\
<50 \% & \end{array}$ & 18 & $75.0 \%$ & 12 & $38.7 \%$ & 15 & $42.9 \%$ & 45 & $50.0 \%$ & & \\
\hline $\begin{array}{l}\text { Moderate } \\
\text { risk } 50-70 \%\end{array}$ & 5 & $20.8 \%$ & 10 & $32.3 \%$ & 11 & $31.4 \%$ & 26 & $28.9 \%$ & 13.423 & $<0.001 * *$ \\
\hline $\begin{array}{l}\text { High risk } \\
>70 \%\end{array}$ & 1 & $4.2 \%$ & 9 & $29.0 \%$ & 9 & $25.7 \%$ & 19 & $21.1 \%$ & & \\
\hline Total & 24 & $100.0 \%$ & 31 & $100.0 \%$ & 35 & $100.0 \%$ & 90 & $100.0 \%$ & & \\
\hline
\end{tabular}

**p-value $<0.001 \mathrm{HS}$ 


\section{Tanta Scientific Nursing Journal}

\section{Discussion:}

Socio-demographic data of the study:

As regards to socio-demographic characteristics of mother of premature infant the research give interested for mother as the most caregiver parent for the baby. The current study showed that most participant of study was mother this may be due to the mother traditionally take more physical and emotional responsibility of care, also mother can tolerate her sons responsibility specially at the first year of age. This finding supported by(Jackson,2013) ${ }^{(13)}$, who stated that the mother experienced higher level of stress than any family members after birth of premature baby. This result consistent with study conducted by (Matricardi\&Montorios, 2013) ${ }^{(14),}$ they showed that mother and father response for the same level of trauma and stress after premature birth.

The present study results indicated that the four fifth of mothers under this study was married. This could be due to the marriage is important social value in Egypt and effect on population structure and other tradition link as child birth and maternity. This finding supported by (Glavin,2016), ${ }^{(15)}$ who stated that women value is strongly tied to fertility and norms of premarital virginity. The finding is consistent with (Cornelia \&Muresan,
2008) ${ }^{(16),}$ who reported that the link between the marriage and childbearing weakened worldwide, evidenced by a sharp rise in birth outside marriage in developed countries in europ.

The current study described that, the slightly more than third of mothers had secondary school level of education were likely increase risk of premature birth more than mothers of low education more likely to increase gestational age. This may be due to awareness prevalence between the people about importance of learning and enhancing educational Level, this finding consistent with (Yang, 2008) ${ }^{(17)}$, who showed that education is an indicator of socio-economic status of person, when mother will educated influence her ability to access and use health care. On the same line the current study showed less than half of studied sample had secondary school education, this result agree with (Petite,

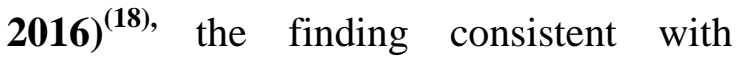
(Wechel et al., 2014) ${ }^{(19) .}$ Who found that the high education play important role in healthy life style and prevent premature birth and his psychological effect on the mother.

the current study revealed that slightly more than half of mothers under this study was worker. This could be due to potential risk factor as high physical work demand also work stressed environment effect on 
pregnancy lead to premature birth, this finding supported by (Zagade,2015) ${ }^{(20) \text {, }}$ who stated that strong associations between high physical work demand and low birth weight also point out that the premature birth due to poorer working condition and job insecurity. This finding is consistent with (Van Melick ,2014) ${ }^{(21)}$ who showed that no clear relation between working condition with premature birth and psychological status of mother.

The present study revealed that the third of uterine age of preterm infant was range from 29-30 weak of gestation this could be due to deviation of period of pregnancy as decrease the period about 32 weeks can cause prematurity and put mother in stressful mood about her baby. This is confirmed with the study carried out by( De magistris et al. ,2010) ${ }^{(22)}$ who stated that, depressive symptoms are associated with lower gestational age, length stay at neonatal intensive care unit and severity of illness.this result also consistent with study carried out by( Kaplan et al. ,2008) $)^{(23) \text {, }}$ who reported that no effect of gestational age on psychological status of mother.

The present study revealed that two third of mothers doesn't have psychological symptom with premature birth. This may be due to the emotional status, mood and strain tolerance differs from women to another. This finding was in agreement with (paulson, 2016) $^{(24)}$ who stated no association between birth weight or gestational age and psychological anxiety or stress or negative self-esteem of mother during pregnancy ,also psychological symptoms can different from person to another in effect and experience. The finding is consistent with (mohammed et al ,2014) ${ }^{(25)}$ who conducted study of very low birth weight and premature delivery among African American women found that high risk of premature birth associated with psychological problem as coping mechanism or anxiety and negative life event during pregnancy.

The current study showed that more than half of mothers under this study had history of previous preterm birth. This could be due to the mother possible exposure to the same circumstances at every time of pregnancy which cause prematurity. this finding supported by. (Bell,2014) $^{(26) \text {, who stated that previous }}$ history of preterm birth and delivery is important risk factor for subsequent preterm birth also effect on psychological status of mother which cause depressive and stress symptom related to prematurity. This finding consistent with. (Tersigini,2014) $^{(27)}$ who stated that the previous history of preterm birth not effect in mother emotion or the subsequent birth. 
The current study indicated that the half of mothers of premature baby at mild risk exposure for depression symptoms. This could be due to thinking at reception the baby and close him in care endows mother good mood and pleasant life. This study supported by (Mohammed,2017) ${ }^{(28)}$ who stated that the post partum depression prevalence in his study the lowest prevalence among region in Egypt, this study consistent with this study consistent with. (Nabil ragab et al ,2015) ${ }^{(29),}$ they showed that the mother of premature baby suffer from high level of depression specially the first four weeks after delivery. The current study showed that two fifth of mothers at risk exposure to high level of stress related to baby admission to neonatal intensive care unit this could be due to the premature birth is traumatic event that cause trauma related symptoms and negative state of feeling such as stress and avoidance from baby condition this study supported by (jonio, 2014)who reported that premature event cause trauma related symptom and high level of stress. this study also supported by (melnyk,et al 2018) ${ }^{(30)}$ who reported that the mother of premature baby experience high stress level and feeling of helplessness in the neonatal intensive care unit and she often lack of adequate knowledge of how interact with her baby.
The current study showed that nearly half of mothers exposure to positive stress related to baby admission to neonatal intensive care unit this could be due to exposure to stress not only have negative impact but also have positive impact as personal growth and self awareness this study supported by (Ormel,2014) ${ }^{(31)}$ who stated that when the exposure to stress Lead to personal growth ,self-reflection and awareness of power ,this study consistent with(wisk,2012) ${ }^{(32)}$. Who stated that stress give impact of negative emotion as pressure ,discomfort and disability to cope with stressful situation.

The current study showed that statistically high significant relation between level of total stress and level of total depression .this finding agreed with study conducted by $(\text { sweet, 2012) })^{(33)}$.who stated that significant relation between level of depression and level of stress ,this study consistent with (wormald ,2015) ${ }^{(34)}$ who stated that no significant relation between total level of depression and total level of stress and increasing level of stress not effect in incident or increase of depression level.

The current study showed that positive correlation and high significant between total score of depression and total score of stress it may be due premature birth is traumatic event cause trauma related 
symptom such as stress and depression .this finding agreed with study of (Bora, 2014) $^{(35)}$. who stated that stress of mother after premature birth mainly associated with depressed mood and depression symptoms.

\section{Conclusion:}

Mothers of neonatal intensive care unit hospitalized infant are emotionally vulnerable and have psychological reaction such as depression and stress . depending on the result of the present study, the following can conclude that regarding the relation between mother's Levels regarding total depression and their sociodemographic the result found there was statistically high significant relation between level of total stress and total depression among mothers under this study, correlation between mother's total score depression and total score of stress show positive correlation and high significant between mother's total score of depression and total score of stress.

VI. Recommendations:

On the basis of the present study, the following recommendations can be drawn:

- Design training programs for mother of premature baby at neonatal intensive care unit such as stress management technique methods, as relaxation technique, meditation, and exercise to increase her tolerance for frustration.
- Educational program for Staff on principle and methods of supporting mother psychologically during staying period in neonatal intensive care unit.

- Appropriate and warm welcome for mother from the time of baby admission and teach some practice of special care, staff role and simple explanation of equipment, also, Create and sustain a healing environment with respect sensory exposure and experience.

- Communicate with mother should regular, understandable, personalized and provide by every member of the team and Continuous evaluation for mother ofilpn baby care such as breast feeding and kangaroo care skin to skin contact.

- Engage in support group to help mother to connect with other who have similar problem and concern.

- psychosocial education programs by providers and hospital administration about prevalence of postpartum depression and its impact and benefits of screening.

- counseling service to early identification of mothers who need referrals for further assessment .

\section{References:}

1. Jonio, c .(2014): Post Traumatic Stress Symptom after Child Birth and Early Mother Child Interaction: An 
Exploratory Study. Journal of Reproductive and Infant Psychology, 32-163-181.

2. Brandon, d, h .(2011): Emotional Responses of Mother of late Preterm and term Infant, Journal of Obstetric, Gynecologic, and Neonatal Nursing, 40[6], 719-731

3. Ahlqvist S.(2014):challenges for the transition into early parenthood :prenatal depressive symptoms ,material distress and the premature birth of an infant dissertations thesis.tuku: university of tuku.

4. Diplasio, p, lonio, e .(2014): Post Traumatic Stress Symptoms after Child Birth and Early Mother-Child Interaction; An Exploratory Study.Journal of Reproductive and Infant Psychology, 32, 163.doi;10.1080/02646838.2013.841880.

5. Clotty, m., dillard, d.m .(2013): Posttraumatic Stress Disorder and Neonatal Intensive Care. the International Journal of Children Education, 28, 23-29.

6. LasiukG .(2013) : An interpretive Description of parental Trauma's Associated with Preterm Birth , Biomed Central Pregnancy and Child Birth 13(1):1-10.

7. Chuffosiwert R, Cline, M .(2015): Implementation of an Innovative Nurse delivered Depression Intervention for Mother of NICU infant. Journal of Psychiatry.15(2), 104-111.

8. Dashti E, Rassouli M, KhanalimojenL .(2014): Correlation betweenDischarge Preparation and Rehospitalization of Premature Newborns;3(4):37-45.

9. CiccoR .2015) :Recommendations for Mental Health Professional in the NICU .J Perinatol;35:s14-s18.

10. Eman, M. (2011): Predictors of morta1ity among neonates admittedto neonata1 intensive care unit in pediatricAssiut University Hospita1 Egypt. Journal ofAmerican Science, ISSN : 1003-1545. (606-611).

11. Berry, J. (1995):The parenta1 stress scale: initial psychometric evidence. Journa1 of socialandpersonal re1ationships, 12:463-472.

12. Wistner, P.(2002) : postpartum depression, N Eng1 J Med; 347(3): 194-199.

13. Jackson k .(2013): Experience of Mother and Father of Premature Infant. Journal of Advanced Nursing, 43, 120-129 doi 10.1046/j.1365-2648 200302686.

14. Matricardi, Montorios .(2013): Mother and Father Differences between Parent in the Reduction Stress Level after Apparent Intervention). $\mathrm{n}$ in a NICU, 
Act A Pediatric, 102, 8-14 doi 10 1111/apa12058.

15. KhalifaD,Glavin K.(2016):

Determinates of Postnatal Depression in sudanes women at 3months postpartum :a cross-Sectional Study .10;6(3):e009443.

16. Cornelia muresan .(2008): Romania: Childbearing Metamorphosis within A changing Context; Demographic Research 19, no.23:855-906

17. Yang j .(2008): Socioeconomic Status in Relation to Selected Birth Defect in Large Multicentre us Case -Control Study. American Journal of Epidemiology, 167(2), 145-154.

18. Petite AC .(2016): Mother Emotional and Posttraumatic Reactions after Preterm Birth: the Mother -Infant Interaction is at Stake 12 Months after Birth. Plosone.11(3):e0151091.doi: 10.1371/journal.pone.0151091

19. WechelmG, Halperinms, Austin j .(2014): Depression and Anxiety Symptom of Mother of Preterm Infant are decreased at 4 Month Corrected Age with Family Nurture Intervention in the NICU. Arch Wommenthealth.19(1):51-61.doi:10. 1007/s00737-015-0502-7.

20. Zagade TB.(2015):A Study to asses the Level of postnatal Depression among postnatal Mothers admitted in the Krishna Hospital ,Karad. International Journal of Science and Research

21. Van melickmj .(2014): Shift Work, Long Working Hours and Preterm Birth: A Systematic Review and Meta Analysis. Environ Health;87(8):83549.doi:10.1007/s00420-014-0934-9.

22. De Magistric A, Coni E, Puddu M, ZonzaM .(2014): Screening of Postpartum Depression:Comparison between Mothers in the Neonatal Intensive care unit and in the Neonatal Section.j Maternal Fetal Neonatal;23(3):101-103.

23. Kaplan LA, Evans L, MonkC .(2008): Effects of Mothers Prenatal Psychiatric Status and Postnatal Cargiving on Infant bio Behavioral Regulation: can Prenatal Programming be Modified ?Early hum dev.;84(4):249-256.doi:10.1016/j. earlhumedev.06.004.

24. Kutner, L. (2016): A Child Embarrassing Acts and Behavior. Psychcentral. retrieved on December 4, 2018. her Child Interaction: an Exploratory study. Journal of Reproductive and Infant Psychology, 32: $163-181$

25. Mohammed E,Mosalem F etal (2014): Predictor of Postpartum Depression among Rural Women in 
Minia,Egypt:An Epidemiological

Study .Public Health ;128(9)817-24.

26. Bell EF , acarreguimj .(2014) :Water intake for Preventing Morbidity and Mortality in Preterm infant; the Cochrane databaseofsystemicreview journal of sychology.12(12):5473815.

27. Tersigni C.(2014): Celiac Disease and Reproductive Disorder :Meta-Analysis of Epidemiologic association and Potential Pathogenic Mechanisms ;Human Reproduction ;20(4)582-593.

28. Mohammed n .(2017): Factor Affecting the Occurrence of Post Partum Depression among Puerperal Women in Sohag city, Egypt. Procobest Gynecol;7(1):4(10).

29. Nabil rm, Ragabaz, el Bahyms, Zeinama .(2015): Psychiatric Disorders in -the Post Partum Period. Menofia med j;28:565-70.

30. Melnykbm, Creanhf, Feinstein nf, Fairbanks e .(2018): Maternal Anxiety and Depression after a Premature Infant Discharge from the Neonatal Intensive Care Unit Explanatory Effects of the Creating Opportunities for Parent Empowerment Program. Nursing Research;57:383-394.

31. OrmelJ .(2014): Mutual Reinforcement between Neuroticism and Life Experience :A-Five Wave ,16 Year Study to Test reciprocal causation ;Journal of Personality and Social Psychology .107(4):751-64.

32. Wisk LD .(2012): Does the Perception that stress affects Health Matter? the Association with Health and mortality .Health Sychol.31:677-84.

33. Sweet 1.(2012): Identification of Parental Stressor in an Australian Neonatal Intensive Care Unit .Neonate Pediatric \&Child Health Nursing, 15(2), 8 .

34. Wormald F .(2015): Stress in parents of Very low Birth Weight Preterm Infants hospitalized in Neonatal Intensive Care Units .A Multicenter Study .Archives Agentinos De Pediatric ,113(4),303-309.

35. Bora S.(2014):Very preterm birth: Maternal Experience of neonatal intensive care environment .journal of perinatology,34(7):555-561. 